\title{
Artesanos emprendedores en la industria textil. Del taller al mercado: El caso del pelaire contestano Bernat Martí (1469-1482)
}

\author{
Enterprising Craftsmen in the Wool Industry. From the Workshop \\ to the Market: The Case of Bernat Martí, Carder of Concentaina \\ $(1469-1482)$
}

\author{
José Antonio Llibrer EsCRIG \\ Universitat de València \\ j.antonio.1librer@uv.es
}

\begin{abstract}
RESUMEN
El presente trabajo analiza la función de un sector del artesanado en el desarrollo y la consolidación de las comunidades pañeras del interior valenciano durante la segunda mitad del siglo XV. Tomando como referencia las comarcas del interior-sur del País Valenciano (la Vall d'Albaida, l'Alcoià y el Comtat, con pequeñas ciudades pañeras como Ontinyent, Alcoi y, especialmente, Cocentaina, donde centraremos nuestro estudio), se analiza cómo un pequeño grupo de artesanos tendía a centralizar y gestionar la actividad textil local mediante su participación directa en el mercado de la lana, tintes y aceite, también mediante el control de las fases de acabado del paño (tundido, abatanado, tintado) y de la misma comercialización de los tejidos sin la intervención de un capital mercantil ajeno a la producción. Mediante el estudio de un ejemplo, el del pelaire contestano Bernat Martí, y a través de la metodologia prosopográfica, ilustramos esta acción coordinadora y gestora del capital industrial local y de su paso progresivo hacia la esfera mercantil.
\end{abstract}

Palabras clave: Industria de la lana, Artesanos emprendedores, Pañeros, Mercado regional. Siglo XV, Cocentaina, País Valenciano.

\begin{abstract}
This article studies the role of a group of craftsmen in the development and consolidation of the woolen towns of the southern interior of Valencia during the second half of the fifteenth century. In certain towns of this area (Vall d'Albaida, Alcoià and el Comtat, and other smaller towns such as Ontinyent, Bocairent, Alcoi and specifically Cocentaina which will be the focus of this study) a small group of craftsmen were able to centralize management of textile activities through direct participation in the wool, dye and oil market. They also controlled the different phases of processing of the cloth (shearing, fulling, and dyeing) as well as the sale of the textiles without the intervention of merchant capital from outside of the sector. With the example of Bernat Martí, woolen carder from Cocentaina, and using a prosopographical methodology, it is possible to study their coordinated action and management of local industrial capital and its progressive shift towards the field of commerce.
\end{abstract}

Key words: Woolen Industry, Enterprising Artisans, Carders, Regional Market, 15th century, Cocentaina, Kingdom of Valencia.

\footnotetext{
${ }^{1}$ Este trabajo se integra en el proyecto «Identidades urbanas Corona de Aragón-Italia: redes económicas, estructuras institucionales, funciones políticas (siglos XIV-XV)», Ministerio de Ciencia e Innovación, HAR2011-28861, dirigido por Paulino Iradiel.
} 
Sumario: 1. Introducción: una villa pañera del interior valenciano. 2.Bernardus Marti, panniparator vicinus Cocentayne. 3. Los negocios textiles de Bernat Martí. 4. Más allá del sector textil: el mercado agrícola y el crediticio. 5. Una valoración de los datos.

\section{INTRODUCCIÓN: UNA VILLA PAÑERA DEL INTERIOR VALENCIANO}

En febrero de 1491, Nicolana, viuda residente en una pequeña ciudad del interior valenciano, inició una inteligente estrategia de inversión: comenzó a prestar dinero a sus vecinos a través del crédito censal. En menos de dos años y medio, mediante la adquisición de siete títulos, llegó a prestar a otros tantos deudores, la nada despreciable cantidad de 6.000 sueldos. En una pequeña villa pañera como era la Cocentaina del finales del siglo XV, con unos 600 fuegos, el negocio de Nicolana no llamó sin embargo la atención porque no hacía sino continuar la estrategia inversora de su esposo, fallecido nueve años antes, Bernat Martí, sin duda uno de los artesanos más activos e influyentes no sólo de la villa sino de su amplia comarca, hacia donde había extendido su actividad no sólo artesanal sino también crediticia y mercantil, con una dilatada trayectoria de venta y distribución de todo tipo productos y capitales. Lana, paños, productos para el tinte, aceite, cereales, vino... eran productos que Bernat Martí, un activo pelaire reconvertido en draper o pañero, vendía con frecuencia a sus vecinos de Cocentaina o a clientes de villas cercanas como Alcoi, Penáguila o Planes, y de centros más alejados como Llutxent, Bocairent, Xàtiva o Vila Joiosa.

¿Pero quién era Bernat Martí? ¿Cuál era su origen? ¿Qué características tenía su empresa artesanomercantil? ¿Cuál fue su estrategia de negocio? Por otra parte, ¿fue el ejemplo de Martí un caso aislado en estas pequeñas ciudades del interior valenciano o fue más bien una estrategia empresarial común a un grupo artesanal más dinámico?

Uno de nuestros objetivos es explicar, en efecto, cómo un activo pelaire vecino de Cocentaina, con un nivel de producción de paños nada despreciable, va redirigiendo poco a poco su empresa hacia la esfera mercantil, aunque sin abandonar su origen manufacturero o pañero, convirténdose en un destacado agente distribuidor, un importante operador económico en un mercado interior que incluía buena parte de la región sur del reino ${ }^{2}$. Sin embargo, el estudio del caso no es un fin en sí mismo, sino que debe permitirnos explicar -y este es sin duda nuestro objetivo clave- cómo funcionaba la producción artesanal de estos centros menores y sus dinámicos mercados asociados - de materias primas, de paños, de productos agrícolas, de capitales- y qué rol estratégico alcanzó el sector de los artesanos emprendedores en el sistema económico local y en las relaciones entre éste y el regional ${ }^{3}$. Y es que, como ya se ha

${ }^{2}$ La trayectoria de este pañero está cerca de seguir los mecanismos de promoción y ascenso económico ya estudiados para la burguesía de la capital del reino, IRADIEL, P. (2009) “«Ego... considerans me devenisse ad maximam penuriam et inopiam». Mecanismos de promoción y pobreza de la burguesía urbana”, en XXXVI Semana de Estudios Medievales, 2009, Estella, pp. 275-305. Y también, NAVARRo, G., «Los negocios de la burguesía en la industria precapitalista valenciana de los siglos XIV-XV», Revista d'Història Medieval, 2000, 11, pp. 67-103.

${ }^{3}$ La dinamicidad de estos sectores artesanales y mercantiles en pequeños burgos o ciudades medias ha generado un cierto interés por el estudio del caso, de ciertas figuras y familias, de medianos empresarios y hombres de negocio, incluso de una incipiente burguesía rural. Por solo citar los de ámbito 
demostrado, la importancia de estos centros "menores", de estas pequeñas ciudades, o "casi ciudades", retomando la expresión de Chitollini -quasi città-, fue determinante para consolidar el tejido industrial y la redes de intercambio que nos llevan al periodo moderno ${ }^{4}$.

Durante el siglo XV, Cocentaina se configuró como una pequeña ciudad de la región meridional valenciana, lejos en buena parte de la acción y la influencia de la capital. Era el núcleo que regentaba un amplio espacio territorial bajo dominio de la familia de los Corella, condes de Cocentaina desde 1448, y que habían adquirido el señorío directamente del patrimonio de la Corona tres años antes ${ }^{5}$. En la segunda mitad del siglo, donde centraremos nuestro trabajo, la villa contaba con unos 550-600 fuegos, lo que supondría una población aproximada de unos 3.000 habitantes. Sin embargo, aquello que destacaba de este pequeño burgo era el sorprendente crecimiento, observable ya en parte desde el último tercio del siglo XIV, de sus actividades

valenciano: Viciano, P., «La promoción social de una familia de mercaderes valencianos. Los Miquel de Castelló en el siglo XV», Hispania, 1993, 185, pp. 971-986; Navarro, G. - Igual, D., «Ontinyent i València en temps de Baltasar Forés», Almaig. Estudis i Documents, 1994, X, pp. 105-109; Aparici, J. -NAVARro, G., «El libro memorial de la tutela del tejedor Joan Fretero (Segorbe 1432-1440)», Estudis Castellonencs, 1997, 7, pp. 231-264; NAVArro, G., «Joan Santalínia i altres paraires de Castelló a la fi del segle XV", V Congrés d'Història i Filologia de la Plana, Castelló, 1998, pp. 155-178. También el conjunto de trabajos recogidos en NARBona, R. et alii, L'univers dels prohoms. Valencia, 1995. Y los trabajos de síntesis, con abundante bibliografía, de IradiEL, P., «En el Mediterráneo Occidental peninsular: dominantes y periferias dominadas en la Baja Edad Media», Áreas, 1986, pp. 64-77; IRAdIEL, P., «Ciudades, comercio y economía artesana», XXV Semana de Estudios Medievales, Pamplona, 1999, pp. 603-658. Y más recientemente Iradiel, P., «Métrópolis y hombres de negocios (siglos XIV y XV)», XXIX Semana de Estudios Medievales, Pamplona, 2003, pp. 277-310. También debe destacarse, CAUnedo, B., «Los «medianos»: mercaderes y artesanos», Medievalismo, 2004, 13-14, pp. 157-180. La extensión de la metodología prosopográfica ha sido uno de los puntos, y no poco importante, que ha permitido buena parte de dichas investigaciones.

${ }^{4}$ La historiografía ha entendido ya que tanto la manufactura para los mercados internos como los intercambios de corto radio, tuvieron para la economía efectos multiplicadores tan importantes como los que generaba la industria dedicada a la exportación y el "gran comercio", hasta el punto que el crecimiento de la manufactura, observado en la larga duración, se sustentó en muchas àreas sobre esta producción interior y sobre un denso y dinámico conjunto de intercambios regionales. Vid. a este respecto, Poussou, J. P. y Loupès, PH. (eds.), Les petites villes du Moyen Âge à nos jours, París, CNRS, 1987; StABEL, P., «Décadence ou survie? Economies urbaines et industries textiles dans les petites villes drapières de la Flandre orientale (14e-16e s.)», en BOONE, M. - PrevenIER, W. (eds.) La draperie ancienne des Pays-Bas: débouchés et stratégies de survie (14e-16e siècles). Actes du colloque tenu à Gand le 28 avril 1992. Bruselas, 1993, pp. 63-82. EpsteIn, S. R., Potere e mercati in Sicilia. Secoli XIII-XVI. Torino, Einaudi, 1996, esp. pp. 182-183; y EpsteIn, S. R., Libertad y crecimiento. El desarrollo de los estados y de los mercados en Europa, 1300-1750, Valencia, PUV, 2009 (orig. 2000). También ARnoux, M. - Bottin, J., «Autour de Rouen et Paris: modelités d'intégration d'un espace drapier (XIII-XVI siècles)», Revue d'histoire moderne et contemporanie, 2001, 48, pp. 162-191. Y ARNouX. M. - BotTIN, J., «Les acteurs d'un processus industriel. Drapiers et ouvriers de la draperie entre Rouen et Paris (XIVXVI siècle)», en Arnoux, M. - Monnet, P. (dirs.) Le technicien dans la citté en Europe occidentale. 1250-1650. École Francaise de Rome, 2004, pp. 347-386. Y los citados antes, Iradiel, P., «Ciudades, comercio...», esp. pp. 649-653; e IRADIEL, P., «Metrópolis...», esp. pp. 238, 288. En relación al debate historiográfico que está generando el diferente rol del gran y del pequeño comercio, una buena síntesis con nutrida aportación bibliográfica, en IGUAL, D., «Operadores económicos y espacios de comercio en el Mediterráneo occidental (siglos XIII-XV)», Revista de Historia Medieval, 2008, 15, pp. 189-214.

${ }^{5}$ Por su aportación documental, todavía resulta necesaria la monografía de Fullana, L., Historia de la villa y el condado de Cocentaina, Valencia, 1920. 
manufactureras en el sector de la lana, llegando a concentrar un colectivo artesanal de más de 350 agentes, y sólo en la segunda mitad del Cuatrocientos -como hemos demostrado con nuestros análisis prosopográficos-; además con un nivel de especialización ciertamente elevado, como lo confirma la existencia en la villa de todo el ciclo de producción pañero (con la consolidación de las fases de refinición: tundido, abatanado y tintado); y con un dinàmico sector artesanal mediante la acción y la consolidación de un importante colectivo emprendedor, no sólo de pelaires, sino también de tundidores, tintoreros y pañeros ${ }^{6}$.

En este período estudiado, la industria textil contestana se nos muestra además sin una reglamentación municipal o señorial que determine sus formas de producción. En efecto, no hay ningún tipo de regulación ordenancista ni tampoco existen veedores u otro tipo de oficiales públicos que ejerzan un control de los bienes producidos. En este contexto cercano a la libre empresa ${ }^{7}$, que sin duda fue una de las causas de su desarrollo, observaremos cómo un pequeño sector emprendedor, nacido del mismo ámbito de la producción - un conjunto de pelaires y tundidores más activos-, desarrollará poco a poco un papel de coordinación y gestión del amplio proceso de producción textil, que les llevará incluso al contacto directo con el mercado, tanto para la adquisición y posterior distribución de materias primas (lanas, tintes, aceite), como para la venta directa de sus paños producidos.

Así, entre esta amplia comunidad manufacturera contestana, los análisis prosopográficos nos han mostrado claramente un grupo de artesanos emprendedores (que llegan a suponer aproximadamente un $12 \%$ del censo artesanal total documentado para la villa), que se caracteriza por controlar la gestión y la propiedad de las infraestructuras necesarias a la producción (tintorerías, batanes, tiradores, almáceras); también porque son propietarios de todo tipo de medios e instrumentos de producción (tijeras y bancos de tundir, telares, urdidores...); ademas observamos cómo convierten sus talleres en auténticos comercios de distribución de lanas y paños, pero también de otras materias primas como aceite o tintes, incluso de productos agrícolas como cereales, vino o ganado; les vemos incrementar su patrimonio con inmuebles rurales o urbanos y con amplias carteras censalistas; además participan repetidamente del gobierno municipal tanto de forma directa, ocupando las magristraturas de la justicia o la juradería, como tomando en arrendamiento impuestos y derechos señoriales; constituyen, en fin, una auténtica élite local, una auténtica burguesía que en estas ciudades medias

${ }^{6}$ Sobre la destacada comunidad artesanal textil en Cocentaina, LliBrer, J. A., Los orígenes de la industria de la lana en la Baja Edad Media. El Comtat en el siglo XV. València, Generalitat, 2007. Y con mayor detalle, Llibrer, J. A., Industria textil y desarrollo regional: la Vall d'Albaida y el Comtat durante el siglo $X V$, (Tesis doctoral inédita), Universitat de València, dirigida por Paulino Iradiel, 2010, vol. II, pp. 25-315. Más recientemente, Llibrer, J. A., «La configuració d'un districte industrial a la baixa Edat Mitjana. Les viles draperes de la Vall d'Albaida, l'Alcoià i el Comtat», Recerques. Història, Economia i Cultura, 64 (en prensa). Entre los años 1470-1505 hemos documentado en Cocentaina 183 pelaires en activo, 39 tejedores, 12 tundidores, 14 tintoreros, 39 sastres, 15 sederos, 20 drapers, 24 mercaderes y 10 artesanos del cuero. Cifras a todas luces significativas para una villa media como ésta. Los números superan, en la misma cronología, los de muchas ciudades de tamaño parecido o incluso mayor como Xàtiva, Alzira, Castelló o Sogorb.

${ }^{7}$ Situación nada extraña en la manufactura medieval peninsular, IRADIEL, P., «Ciudades, comercio...», esp. pp. 657-660; e Iradiel, P., «Metrópolis...», esp. pp. 292-294. 
salta a la luz con mayor claridad si cabe que en las grandes metrópolis ${ }^{8}$. La vida y los negocios de Bernat Martí son un excelente ejemplo para analizar este interesante proceso de crecimiento, jerarquización y diversificación que se da en las comunidades artesanales de muchas villas valencianas. Jerarquización que no es sino un reflejo de los diferentes tipos de empresa manufacturera que se iban diferenciando entre los menestrales de estas pequeñas ciudades, y de los que hablaremos a contiuación.

Como ya hemos visto, centramos nuestro estudio en la villa de Cocentaina pero parecidos parámetros -tanto demográficos como socioproductivos- pueden encontrarse en pequeñas ciudades de esta región, como la vecina Alcoi o la más alejada Ontinyent y, en menor medida, Bocairent, Albaida o Planes. Se trata un conjunto de centros de segundo orden donde va articulándose una red de talleres artesanales dedicados a la confección de paños, y que en su conjunto acaban configurando lo que podría ser un incipiente distrito industrial, o un área de clara vocación manufacturera ${ }^{9}$. Tal espacio acaba beneficiándose de la integración de los mercados meridionales del reino, tanto de materias primas -lana esencialmente, pero también tintes o aceite- como de bienes de consumo, que en esta cronología se manifiestan en claro crecimiento. Así, el aumento considerable de la demanda de productos textiles en las ciudades, villas y comunidades campesinas del sur valenciano, está en la raíz del desarrollo de este activo distrito artesanal. No es momento de analizar aquí las causas que propiciaron el desarrollo de esta zona manufacturera; fue sin duda la conjunción de diversos factores la que lo produjo: el primero partió lógicamente del lado de la demanda, fue la configuración de un amplio mercado consumidor en toda la zona meridional del reino, como puede comprobarse con el crecimiento demográfico de

\footnotetext{
${ }^{8}$ Navarro, G., «Los negocios de la burguesía...», esp. pp. 81-88, e Iradiel, P., «Metrópolis...», esp. pp. 291-308.

${ }^{9}$ Nuestros análisis prosopográficos que, más allá de la misma Cocentaina, se han adentrado en estas otras villas artesanales, nos permiten hablar de un conjunto manufacturero formado por al menos unas seiscientas unidades artesanales para la segunda mitad del siglo XV, LLIBRER, J. A., Industria textil y desarrollo regional..., vol I, esp. pp. 179-224, y el amplio apéndice prosopográfico del vol. II, pp. 15315. También Llibrer, J. A., «La configuració d'un districte industrial...» (en prensa). En el momento que completemos los análisis prosopográficos mediante el vaciado total de la documentación aún pendiente de estas otras villas del área - tarea que estamos realizando-, las cifras de artesanos y talleres textiles serán, sin duda, mayores. Además, el dato cuantitativo del número de molinos pañeros ubicados en esta zona (en aumento desde la segunda mitad del siglo XV, y que llega a 38 batanes a principios del siglo XVI) es más que determinante para hablar de su desarrollo textil: se trata de la concentración de batanes más amplia de todo el reino, incluso superior al área de la propia ciudad de Valencia, MiRA, A., Entre la renta y el impuesto. Fiscalidad, finanzas y crecimiento económico en las villas reales del sur valenciano (siglos XIV-XVI). València, PUV, 2005, esp. pp. 53-72. Y también, LlibreR, J. A., «La gestió dels batans i el desenvolupament de la indústria tèxtil al segle XV. El cas de l'àrea Alcoi-Cocentaina», Estudis d'Història Agrària, 2012, 23, pp. 231-248. Otro tema es discernir qué relación o jerarquía se establece entre los centros de esta región artesanal (y especialmente entre Alcoi-Cocentaina-Ontinyent, que se configuran como las más potentes comunidades pañeras). Buena parte de la historiografía, que ha partido de una observación del fenómeno industrial -fabril- contemporáneo ha creído que Alcoi fue el centro rector del desarrollo textil de toda la zona, sin embargo, nuestros análisis prosopográficos han demostrado que Cocentaina no sólo concentra un mayor número de unidades de producción, además su élite artesano-mercantil llega a establecer vínculos de cierta intervención sobre la producción o la venta de paños de las otras villas, LliBrer, J. A., Industria textil y desarrollo regional..., vol. I, pp. 210-224; el caso de nuestro pañero Bernat Martí, con sus amplios negocios comarcales, es también significativo en este aspecto.
} 
todas estas comarcas y villas del sur valenciano a lo largo de pràcticamente toda la centuria ${ }^{10}$; por otro lado, la potencialidad de una gran zona ganadera asentada en esta misma región, las sierras de Mariola, Guadalest, Seta, Confrides, etc., facilitó el acceso a la materia prima por parte de estos pequeños talleres artesanales, mientras que un aumento de las rentas agrarias, de la productividad agrícola, en el marco de la pequeña explotación campesina - como ha estado ya demostrado por algunos autores $^{11}-$, permitió el trasvase sectorial de mano de obra y la multiplicación de pequeñas unidades manufactureras de tipo familiar.

Pero volvamos de nuevo a la capital del Comtat. Cocentaina será, en efecto, nuestro observatorio privilegiado, uno de estos núcleos de ajustado contingente demográfico donde, por ello mismo, será más sencillo el seguimiento de los artesanos, sus familias y linajes, sus negocios, sus operaciones, su patrimonio, su vida pública y su acción política. Un nutrido conjunto de fuentes conservadas nos han ayudado: más de cincuenta protocolos de distintos notarios que trabajaron en la villa durante la segunda mitad del Cuatrocientos; registros de las actas municipales, los Manuals de Consell; más de una docena de libros judiciales, los de la Cort del Justícia, oficial que actuaba como juez de primera instancia; e incluso parte de la documentación señorial de los Corella en relación a su gestión del condado. Este grupo de fuentes de diverso origen nos ha permitido el cruce de todo tipo de información sobre los vecinos de la villa, especialmente los artesanos y mercaderes, para elaborar unas amplias y detalladas prosopografías, que se convierten en un índice altamente significativo de la estructura productiva de la villa de Cocentaina: pensemos que en total hemos localizado 387 individuos, entre artesanos y mercaderes, y únicamente entre los años 1470-1505, para una comunidad que, como indicábamos antes, contaba unos 550-600 fuegos ${ }^{12}$.

${ }^{10}$ Sobre el crecimiento demográfico que durante buena parte del siglo XV se gesta en esta zona sur, Iradiel, P., «L'evolució econòmica (segle XV)», en De la Conquesta a la Federació Hispànica. Historia del País Valencià, Barcelona, Edicions 62, 1989, vol. II, pp. 267-324. Y también Cruselles, E., «Dinámica demográfica, red urbana e inmigración ciudadana en la Valencia bajomedieval», Saitabi, 2003, 53, pp. 35-56.

${ }^{11}$ Mira, A., Entre la renta y el impuesto..., esp. pp. 100-116. Sin duda uno de los puntos clave que permite entender y explicar la concentración artesanal textil que se documenta en estas villas del interior-sur valenciano es la favorable coyuntura de crecimiento que experimenta la actividad agrícola. Los índices de recaudaciones fiscales -analizados detalladamente por Mira durante el siglo XV y principios del XVI- denotan aumentos cíclicos de diferente intensidad pero que permiten hablar de un largo periodo de crecimiento (moderado durante buena parte del Cuatrocientos pero intenso desde el último cuarto). El desarrollo de la pañería no puede explicarse obviando estos datos. Las pequeñas explotaciones campesinas de estas villas, sobre la base de una agricultura sustentada en la trilogía mediterránea (cereales, vino, aceite, productos omnipresentes en las transacciones de los grandes artesanos emprendedores como Bernat Martí) fueron capaces de optimizar sus recursos para generar un desarrollo sostenido de la productividad. Esta optimización fue la que permitió la liberación de activos y el desvío sectorial de mano de obra, dando lugar de esta forma a la multiplicación de nuevas unidades artesanales y a la extensión de la manufactura pañera en sus distintas operaciones y procesos.

${ }^{12}$ En el segundo volumen de nuestra tesis doctoral ofrecemos los listados y el desarrollo prosopográfico de este importante colectivo socioprofesional, que se completa además con las prosopografías del grupo de artesanos y operadores mudéjares de la propia aljama contestana, en total 108 individuos más que mantienen constantes negocios con el grupo manufacturero cristiano, vid. LliBrer, J. A., Industria textil y desarrollo regional..., vol. II, pp. 15-340. 


\section{BERNARDUS MARTI, PANNIPARATOR VICINUS COCENTAYNE}

Y entre todas estas trayectorias profesionales, la de Bernat Martí se nos muestra como una de las más destacadas y significativas, tanto por su constante presencia en las fuentes, como por su volumen de negocio, por su diversificación empresarial, por su vocación mercantil y por su estrategia crediticia. De Martí llegamos a saber mucho porque su presencia en la documentación es constante, sobre todo en la mesa de distintos notarios de la villa, y particularmente en la de Guillem Peris -algo así como su notario personal, que llegará a redactar buena parte de los documentos que exigían sus numerosos negocios, e incluso su propio testamento e inventario-. Todo este acopio documental es reflejo lógicamente de una intensa actividad económica que, como veremos, va mucho más allá del ámbito estrictamente local ${ }^{13}$.

Las primeras noticias directas que localizamos de Bernat aparecen en el segundo protocolo de Peris, de los años 1469-1470, y en ellas Martí simplemente aparece actuando como testigo en negocios textiles -venta de paños- que llevan a cabo otros pelaires contestanos, lo que podría permitirnos la deducción de ciertas relaciones laborales entre dichos artesanos. No obstante nuestro protagonista estaba ya en condiciones de desarrollar una carrera profesional propia e independiente, porque sólo un año después es ya localizado vendiendo un paño a otro pelaire de la misma villa, Francesc Porta: se trata de un paño de calidad, un «veintiuno» - es decir, de veintiún centenares de hilos en la urdimbre- aunque sin tintar, y que es valorado por un total de 180 sueldos. Desde este momento, Martí comenzará a desarrollar una intensa actividad productiva y mercantil que lo llevará a diferentes negocios y al trato directo con clientes de villas y lugares muy diversos ${ }^{14}$.

Y ya desde las primeras noticias, Bernat nos aparece como pelaire y vecino de Cocentaina -panniparator Cocentayne vicinus ${ }^{-}$, vocación que posiblemente le llegó desde su propio ámbito familiar, dado que su padre, Pere Martí, fue pastor. El contacto de este pastor con los pelaires que adquirían lana le facilitó tal vez el acceso a algunos de esos talleres para su formación en las técnicas de la parairia, siguiendo los cauces habituales explicitados en los contratos de servicio o aprendizaje. No conocemos tal contrato para el caso que nos ocupa, pero en una pequeña ciudad como era la Cocentaina de mediados del XV, lo más frecuente era llevar a cabo tales relaciones de servicio sin una escrituración notarial; el conocimiento de las partes, asentado en una intensa relación de vecindad, permitía tal confianza y el ahorro de la gestión ante notario ${ }^{15}$. Además, no debemos olvidar que el propio Bernat pudo formarse y adquirir

13 Hemos llegado a localizar sobre este pelaire un total de 106 noticias en sólo doce años, de 14701482 (año de su muerte según indica la redacción de su inventario), lo que llega a constituir una de las prosopografías más amplias de nuestro estudio. Tras su muerte, documentamos algunas noticias más de los negocios de su viuda, como la adquisición de censales indicada al principio.

14 A partir de ese año 1471, Martí ya no aparecerá como testigo en los documentos notariales sino llevando a cabo sus propias gestiones y negocios.

15 En la intensa prospección documental que hemos llevado a cabo en Cocentaina, entre $1470 \mathrm{y}$ 1505, sólo hemos localizado 16 de estos contratos, mientras que hemos llegado a documentar más de 70 jóvenes trabajando o sirviendo en casa ajena. Prescindir del notario -y del gasto que ello suponíaparecía así una costumbre en estas villas, LliBrer, J. A., Industria textil y desarrollo regional..., vol. I, pp. 491-519. 
el conocimiento técnico de la pelairía con otros artesanos de su propia familia. Los Martí son, en efecto, uno de los linajes con más tradición artesanal pañera de la villa: ya en la década de 1420 localizamos a Jaume Martí, panniparator vicinus ville Cocentayne, y a Pere Martí, draperius vicinus Cocentayne, que tuvo cierta relevancia política: era miembro del Consell General y fue síndico de la villa en 1424. Posteriormente llegamos a contabilizar un total de seis miembros del linaje de los Martí, algunos contemporáneos de nuestro protagonista, desarrollando la actividad de la pelairía ${ }^{16}$. Así Bernat Martí no hizo más que seguir una tradición laboral familiar iniciada muchas décadas antes, aunque tuvo la iniciativa de abrir nuevas vías de negocio y redirigir su empresa hacia otras actividades, algunas relacionadas con la producción textil (como su implicación en el tintado o la venta de paños), otras ajenas a su profesión original (la distribución de todo tipo de productos agrícolas o la configuración de una amplia cartera de inversión crediticia).

Pero, a pesar de la tradición familiar, y de su supuesta formación en alguno de los talleres de familiares o vecinos, el inicio de la empresa artesanal propia exigía una mínima aportación para la adquisición de los medios de producción necesarios (instrumental básico, materia prima... y un pequeño espacio para desarrollar la actividad). El matrimonio, la fundación de una nueva unidad familiar, se ha considerado como el arranque de un nuevo taller. Las aportaciones que se realizaban por ambas partes -por ambas familias que entraban en contacto- eran suficientes para este arranque productivo. Gracias a su testamento, redactado el 18 de marzo de $1482^{17}$, sólo dos días antes de su muerte, sabemos que Martí contrajo matrimonio con la ya comentada Nicolana, hija de Joan Pérez Monyno, perteneciente a una activa familia de pañeros bien relacionados socialmente: aunque desconocemos el oficio de Joan Pérez Monyno -el suegro de Martí- sabemos que su hermano Bartomeu era pañero (paraire draper es el término que aparece en la documentación) ciudadano de Valencia; por otro lado, el hijo de Joan Pérez, y hermano de Nicolana, era también draper que se avecindó en Valencia a principios de la década de $1470^{18}$. Sin duda el enlace Martí-Pérez Monyno

${ }^{16}$ Sobre este importante linaje de pelaires contestanos, y de otros con similares intereses pañeros y estrategias, LliBRER, J. A., «La indústria tèxtil contestana al segle XV. Històries d'artesans i exercici prosopogràfic», Alberri, 2007, 18, pp. 9-49. La tasa de reproducción de oficios del grupo artesanal en estas villas medias es elevada (algo más del $80 \%$ en los casi 400 casos estudiados, es decir, los hijos tendían a desarrollar idéntica actividad que sus padres), y sobre todo en el ámbito de la pelairía. Los mismos oficios no sólo pasaban de padres a hijos sino también quedaban dentro del propio linaje, del grupo familiar: uno de los hijos de Martí, Pere, será pelaire, sin embargo el otro, Miquel Joan, será mercader (así nos aparece desde el principio en sus numerosos negocios documentados de ámbito supracomarcal), vid. sus prosopografías en LliBRER, J. A., Industria textil y desarrollo regional..., vol. II, pp. 192-194. Otro punto interesante es explicar porqué la parairia generaba esta continuidad generacional y familiar: sin duda las posibilidades que ofrecía por la diversidad de operaciones que desarrollaba y que estaba en disposición de gestionar (desde la compra de lana hasta la venta del paño) están en el origen de tal continuidad. Por esta razón no es casual que los artesanos más activos y emprendedores nazcan de este colectivo y que acaben con frecuencia como mercaderes pañeros.

${ }^{17}$ Archivo de Protocolos del Patriarca de Valencia (APPV), notario Guillem Peris, sig. 23.807.

${ }_{18}$ En 1473 este draper Bartomeu Pérez Monyno, cuñado de Martí, nos aparece ya como civis Valencie. Su trayectoria es también interesante, pues lo encontramos numerosas veces vendiendo paños -tintados y sin tintar- aceite, ganado, y prestando dinero en el mercado local y comarcal; muestra además ciertas estrategias de ascenso social: contrae matrimonio con Montserrat, hija del notario contestano Miquel Pérez; nombra procurador a su tío, el draper vecino de Valencia antes comentado; y 
nace y se gesta con una clara vocación pañera (¿posible asociación productiva?, ¿posible complementariedad empresarial?), y se nos muestra así como una calculada estrategia por parte de las dos familias para el fomento del negocio textil. Las cifras del enlace de Martí nos aparecen en el testamento citado: la esposa aportó 4.500 sueldos de dote, y Bernat 2.250 de creix. Aunque no podemos precisar el detalle del contenido de la dote, la cantidad total aportada -6.250 sueldos- $^{-}$parece más que suficiente no sólo para iniciar la empresa artesanal propia, incluso para planterarse la posibilidad de mayores negocios que pudieran exigir alguna inversión complementaria. Además, el montante de la dote (225 libras) es lo suficientemente significativo para que lleguemos a algunas interesantes deducciones sobre el nivel socioeconómico en el que nuestro protagonista $-\mathrm{y}$ su empresa- comenzaban a situarse.

En efecto, la comparación de estas cantidades con las aportadas en algunas de las escalas socioprofesionales conocidas para otros ámbitos cercanos, nos muestra el nivel elevado en el que ya se ubicaba la nueva familia de Martí. En la misma cronología en la que nosotros trabajamos, las investigaciones de José María Cruselles indican que las dotes documentadas para artesanos de la ciudad de Valencia ofrecían una media de 80 libras (con un máximo de 500 y un mínimo de 5 libras); mientras que las dotes del grupo mercantil suponían una media de 195 libras (máximo de 600, mínimo de 40) ${ }^{19}$. La comparación con estas cifras nos remite al alto valor de la dote que recibe Martí, que parece estar ya al nivel de las del colectivo mercantil, colectivo hacia el cual aspiraba y al que redirigirá su carrera profesional. Y si acercamos nuestra mirada al mercado dotal de la misma Cocentaina, observamos que las 225 libras que aporta Nicolana se sitúan en la media de las dotes artesanales que, por otro lado, resultan sorprendentemente elevadas si las comparamos con las de la capital del reino, y denotan el nivel y la capacidad de la industria contestana y de la incipiente burguesía local que se consolidaba bajo esa actividad pañera ${ }^{20}$.

Es decir, desde el principio Martí parece ya buscar -al menos si analizamos su enlace matrimonial- su asentamiento en el grupo de los artesanos más activos y con mayores y más diversificadas empresas, de los agentes más emprendedores de una

finalmente se traslada a la capital, aunque no abandona sus negocios contestanos. Vid. su prosopografía en Llibrer, J. A., Industria textil y desarrollo regional..., vol. II, pp. 242-243.

${ }^{19}$ La detallada investigación en CRUSELles, J. M., «Ideales sociales y estrategias familiares en el mundo urbano (la ciudad de Valencia, 1485-1500)», en La burguesía española en la Edad Moderna, Madrid, 1996, vol. II, pp. 1369-1383, esp. 1371-1373. El autor indica además que sólo el $29 \%$ de las dotes artesanales superaban la cantidad media de 80 libras, y que sólo el $14 \%$ de los artesanos recibía dotes superiores a las 125 libras. Navarro confirma estas mismas cifras dotales para el sector del artesanado de la seda también en la capital, vid. NAVArro, G., Los orígenes de la sedería valenciana (siglos $X V$-XVI), Ajuntament de València, 1999, esp. pp. 132-135.

${ }^{20} \mathrm{La}$ media en Cocentaina de dotes artesanales es de 195 libras (entre 1.000 y 15 como valores extremos). El estudio del mercado matrimonial contestano nos ha permitido diferenciar dos colectivos artesanales distintos: por un lado, los grandes artesanos, más activos y emprendedores, con mayor volumen de negocio y capitalización (que recurren al sistema dotal, y con cantidades superiores a las 200 libras; lo que supone un $15 \%$ del colectivo artesanal); y los artesanos más modestos, con actividad más limitada y empresas más humildes (que recurrían simpre al sistema de germania, y con cantidades nunca superiores a las 80 libras). En Cocentaina el uso del sistema dotal se nos revela claramente como más propio de los artesanos poderosos, de los grandes linajes artesanales, con mayor nivel patrimonial y capacidad económica, LliBrer, J. A., Industria textil y desarrollo regional..., vol. I, pp. 520-556. 
villa manufacturera como era la Cocentaina de la segunda mitad del siglo XV. La posterior trayectoria de sus negocios confirmará tal objetivo ${ }^{21}$.

\section{LOS NEGOCIOS TEXTILES DE BERNAT MARTÍ}

La valoración de la empresa de Martí, y en general -no lo olvidemos- de este selectivo grupo de artesanos emprendedores, pasa por el análisis de su especialización profesional, de su capacidad de producción, de sus vías de negocio y estrategias de inversión, y de su contacto directo con el mercado. Para el caso de Martí disponemos, junto a la elevada colección de noticias -106 en total- como ocurre con otros activos artesanos-empresarios contestanos ${ }^{22}$, de su inventario de bienes, documento tan útil como escaso en las fuentes ${ }^{23}$. De esta forma podemos acceder directamente a su taller, a su botiga de paños, a su actividad, a sus estrategias de gestión, podemos conocer los productos que tenía en almacén, sus libros de contabilidad, etc.

Antes indicábamos que Martí nos aparece desde el principio como pelaire, y que tendría una formación como tal, pero la amplitud de tareas y operaciones que implicaba la pelairía ${ }^{24}$, nos plantea algunas preguntas: ¿en qué procesos concentró su actividad? ¿cuál era realmente su especialización y cómo evolucionó ésta a lo largo de su trayectoria? Sus negocios constantes de ventas de paños hasta el final de su carrera nos indican que nunca abandonó la pelairía ${ }^{25}$, pero ¿de qué forma se relacionaba con estas actividades, con el trabajo directo en el obrador? La primera noticia localizada

${ }^{21}$ En su mismo testamento Martí nos indica las cantidades con las que se deberá dotar a sus tres hijas (Úrsola, Isabel y Margarida) y vuelve a situarse, en un intento de mantener a su numerosa familia en el status conseguido, en cantidades nada despreciables: 250 libras; mientras que para los dos varones indica todavía una cifra mayor, 300 libras, que serán entregadas en todos los casos en metálico o títulos censales. Un futuro hijo que le nacerá en pocos meses, recibirá idéntica cantidad. En total Martí prevé la donación, por los distintos matrimonios, de unos 32.000 sueldos. Interesante detalle para valorar su patrimonio final.

${ }^{22}$ A título simplemente indicativo: del draper Joan de Calatayud (documentado entre 1471-1502) hemos localizado 64 noticias; del pelaire-draper Joan Moltó (1470-1505), 71 noticias; del también pelaire-draper Joan Pérez de Requena (1470-1500), 61 noticias; y unas 45 noticias han sido localizadas del pelaire-draper Gabriel Bosch, de los tintoreros Francesc de León y Pere Maroquí, y del pelaire Pere Pérez de Requena. Todos son vecinos de Cocentaina, y presentan idénticas características en cuanto a volumen de negocio y competencia empresarial que el mismo Martí: participación activa en el mercado (de lana, tintes, aceite, paños, productos agrícolas, ganado), actividad crediticia, propiedad o gestión de molinos, batanes, tintorerías o tiradores, presencia en el gobierno municipal y en los arrendamientos señoriales.

${ }^{23}$ APPV, 23.807, notario Guillem Peris, 1482-IV-12. Documento transcrito completo en LLIBRER, J. A., Industria textil y desarrollo regional..., vol. II, pp. 431-441. Una valoración sobre estas fuentes, IRADIEL, P., "Fuentes de derecho privado: protocolos notariales e historia económica", en Ammannati, F. (ed.) Dove va la storia economica? Metodi e prospettive sec. XIII-XVIII. Istituto Internazionale di Storia Economica, Florencia, 2012, pp. 225-248.

${ }^{24}$ Sobre las numerosas tareas relacionadas con la pelairía, Iradiel, P., Evolución de la industria textil castellana en los siglos XIII-XVI. Factores de desarrollo, organización y costes de la producción manufacturera en Cuenca, Salamanca, Universidad, 1974, pp. 186-208.

${ }^{25}$ Sólo un mes antes de su muerte, documentamos una venta de seis alnas de paño a Jaume Sebastià, agricultor de Penáguila, APPV, 23.807, notario Guillem Peris, 21-II-1482. 
sobre Martí nos pueden dar la clave de su especialización dentro de la pelairía: es de 1469, y en ella aparece como tundidor-Bernardus Martí, pannitonsor-26. Aunque posteriormente ya no se citará nunca a Martí con esta especialización (será consignado de nuevo como paraire o bien como draper $^{27}$, estos detalles nos indican que nuestro artesano concentró desde el principio su trabajo en el tundido, es decir, quiso estar cerca de las selectivas operaciones de acabado del paño, interés que en el futuro se nos confirma porque sabemos que participó también activamente en el tintado de paños, a través de la formación de compañías con tintoreros de Cocentaina; a su vez, este interés en las selectivas y complejas fases de refinición del paño, le llevó lógicamente al contacto con la esfera mercantil, y a la comercialización del producto acabado.

Gracias a su inventario podemos confirmar todos estos puntos: poseía unas tijeras y un banco para el tundido de los paños (unes tisores de baxar ab son tauley de baxar) junto a una gran cantidad de paños y fragmentos de paño (a través de alnas sueltas, lo que testimonia a su vez la venta de tejido al por menor); además el notario nos indica que en una caja de madera tenía algunos libros de contabilidad, en concreto uno del negocio de venta de paños y otro de la compañía del tintado (certs llibres manuals de la draperia e companyia del tint e altres negocis e negociacions, los quals són cuberts de pergami $)^{28}$. Todos estos bienes, tanto los paños y telas almacenadas - de los que después hablaremos-, como los intrumentos de tundido y sus libros de cuentas, estaban en una estancia concreta de la casa, en su botiga, y así lo especifica con todo detalle el notario: Primo, en la botiga de la casa del dit en Bernat Martí, hon aquell solia tenir los draps de llana, fonch atrobat los béns següents ${ }^{29}$. Hay que interpretar esta botiga, sin duda, como espacio para el trabajo pero, sobre todo, para la venta, a juzgar por la gran cantidad de paños y de fragmentos que Martí tenía en stock. En

${ }^{26}$ En una procuración en la que el mercader contestano Bernat Cirera nombra al traginero vecino Joan Monfort, aparece Martí como testigo con esta denominación (APPV, 23.799, Guillem Peris, 1469VI-21).

${ }^{27}$ En 1471 encontramos un dato muy interesante en relación a la evolución de su empresa: en una venta de aceite que realiza nuestro protagonista (50 arrobas -607 litros- a los hermanos Aborix, de Cocentaina), el notario Miquel Pérez tacha la denominación de baxador para sobrescribir draper como oficio de Martí (AMC, M-42, notario Miquel Pérez, 1471-XII-13).

28 APPV, 23.807, notario Guillem Peris, 1482-IV-12. A parte de estos libros, el notario indica posteriormente la presencia de otros dos: uno en el que Martí lleva la contabilidad del pago de pensiones de sus 44 títulos censales (fonch atrobat un capbreu o memorial de censals, en lo qual són escrits los censals); y otro libro, que el notario denomina libre de la botiga, donde hay anotadas distintas partidas de ingresos y gastos (hun libre de la botiga del dit en Bernat Martí, lo qual és en forma de full ligat en pergami, en lo qual hi ha cartes scrites axi de partides barrades com sens barrar e linear).

${ }^{29}$ El notario especifica con detalle todos los espacios que conforman la casa de Martí. A todas luces se trata de una vivienda de grandes dimensiones y con diferentes zonas de negocio y almacenamiento: se distinguen hasta quince espacios distintos (botiga, comedor, almacenes de aceite y de vino -celler de l'oli, celler del vi-, cocina, patio con pozo; en el piso superior encontramos cinco habitaciones: una sobre la botiga, una sobre los almacenes de aceite y vino, otra sobre el comedor, dos junto a la escalera; otras dos más pequeñas, y dos más en un tercer nivel donde guardaba carbón). En su extenso inventario, el notario comienza su descripción de bienes precisamente en la botiga, ¿simple casualidad?, ¿entiende tal vez el notario que ésta es la zona más importante y que contiene lo más preciado de la casa?, ¿o es el primer espacio al que se accede de la vivienda desde la vía pública para facilitar el contacto con los clientes? APPV, 23.807, notario Guillem Peris, 1482-IV-12. 
total nuestro protagonista guardaba dos paños sin tintar, ambos de pinte alto -uno veintiuno y otro dieciocheno-, pero junto a éstos disponía de más de 170 alnas de diferentes tipos de paños y tejidos, y de diferentes colores (verde oscuro y claro, azul oscuro, morado, negro ${ }^{30}$. Hablamos, en referencia a esta botiga, de un espacio que bien podía definirse como taller-tienda ${ }^{31}$, y donde Bernat vendía tanto los paños completos (así lo sabemos por sus constantes ventas que aparecen en otras fuentes), como fragmentos al por menor de paños ya tintados a través del corte de distintas alnas. La venta de paños completos no excluía la distribución de tejidos al detalle, lo que obligaba a este pelaire-tundidor a una dedicación cada vez mayor al sector de la mercatura.

No obstante, la lectura siguiente del inventario nos descubre un dato muy interesante: avanzada la descripción de los objetos -y alejados ya de la botiga que, recordemos, fue detallada en primer lugar-, en una de las habitaciones del piso superior, justo la que se sitúa sobre el comedor, encontramos un urdidor y un torno (hun ordidor e hun torn), herramientas básicas para el primer tratamiento de la lana. Sin embargo, el hecho que estuvieran depositadas en una habitación superior, alejada de la botiga, y con función de almacenaje (junto a estos instrumentos había 30 cahíces de trigo -

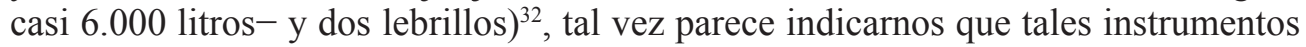
estaban también almacenados y que no se les daba un uso continuado. Podríamos pensar que Martí trabajó con ellos en su inicio profesional dentro de la pelairía, y que con el paso de los años y la evolución de sus negocios quedaran arrinconados en un espacio marginal. También podríamos interpretar que se trataba de instrumentos de uso femenino, dada la asociación de la mujer con estas tareas inciales de preparación de la lana antes del tejido ${ }^{33}$.

Analicemos el resto de los negocios de nuestro protagonista para concretar mejor cuál fue la evolución de su actividad profesional y de su empresa. Para ello el uso de la metodología prosopográfica se revela como fundamental, aunque el problema está en la ausencia de noticias sobre Martí antes de 1470, momento en que su empresa posiblemente ha alcanzado ya una dedicación amplia en la esfera mercantil, como nos muestra su misma prosopografía. Desde ese año, la actividad que supone más volumen de negocio es la venta de paños que, aunque genera 31 de las 106 noticias recuperadas (cifra superada por la compraventa de aceite: 33 noticias), da lugar a transacciones de mayor valor económico (el valor mínimo es de 109 sueldos, precio

${ }^{30}$ Disponía, sólo en la botiga, de 174 alnas: 120 de lana (de paños dieciochenos, y todos tintados), 46,5 de lienzo (sin especificar) y 7,5 de camelote. Pero más allá de la botiga, en una de las habitaciones superiores, encontramos 120 alnas más de lienzo junto a 20 libras de hilo y diez madejas de fil de Flandes, lo que parece testimoniarnos, como veremos después, que distribuía hilo a tejedores de la villa para la elaboración de sus paños. Dejamos fuera de todos estos recuentos las telas que formaban parte del ajuar doméstico.

${ }^{31}$ La acepción de botiga como taller-tienda no era infrecuente en el catalá medieval, vid. AlCover, A. M. y Moll, F., Diccionari Català-Valencià-Balear. Mallorca, 1993.

32 Item, en la tercera cambra damunt lo megador, foren atrobats XXX cafiç de forment; item, hun ordidor e hun torn; item, dos librells migançeres.

${ }^{33}$ Otra posibilidad, sobre la cual tenemos algún indicio, es que se tratara de utensilios que Martí podía dejar a otros artesanos más humildes a los que encargaba la tarea de preparación de la lana. Con posterioridad hablaremos también de este punto. 
de un paño dieciocheno sin tintar) $)^{34}$. Todos los paños que vende son, en efecto, de cuentas altas, de calidad, dieciochenos o veintiunos, como los que tiene almacenados en su botiga, y con precios que van de los citados 109 sueldos de un 18no sin tintar, a los 240 sueldos que cuesta un 21 no negro ${ }^{35}$. Incluso cuando vende alnas sueltas, el precio es más elevado si cabe: entre 12 y 8 sueldos por alna, aunque en estos casos el tejido está ya tintado, lo que nos acerca al valor de lo que Martí tenía almacenado en botiga ${ }^{36}$.

Por otra lado, aunque no conocemos el valor de muchos de sus tejidos vendidos, Martí solía distribuir los paños (y lógicamente las alnas) ya tintados, y de tonos negro, azul, verde o amarillo oscuro. Si hacemos un cálculo con los paños que tenía en tienda y con los localizados en los reconocimientos de deuda, podemos concluir que Martí vendía el 70\% de los paños -completos o en fragmentos- ya tintados; es decir, el valor merceológico de los productos que vendía en estas comarcas del interior era realmente elevado. Y estaba en condiciones de hacer esto, y así de acceder al mercado con esta importante ventaja sobre otros pelaires, gracias a su acercamiento a la tintura a través de la asociación con tintoreros mediante compañías. Lógicamente Bernat no conocía los secretos de la tintura, ni disponía del complejo instrumental ni instalaciones para llevar a cabo tales operaciones -así lo hemos deducido claramente por su detallado inventario-, pero tuvo la iniciativa, el sentido emprendedor, de acordar esta relación profesional con los expertos de la coloración del paño. Su dedicación inicial a la fase de acabado o tundido, y su interés por distribuir directamente sus propios tejidos, le acercó a los tintoreros para así aumentar la valor añadido de sus productos y situarlo en el mercado en condiciones más favorables ${ }^{37}$.

En estas compañías para el tintado de paños, relativamente frecuentes en Cocentaina para la segunda mitad del siglo XV -lo que nos indica de nuevo la madurez que había alcanzado la industria textil contestana-, se producía una interesante asociación de capital y trabajo: por una parte, se distinguía un socio que se encargaba de las tareas administrativas y mercantiles (compra de productos tintóreos, contabilidad,

${ }^{34}$ Tal vez pueda pensarse que el número de ventas de paños localizadas de Martí es escasa tratándose de un arco cronológico que va de 1471 a 1482, no obstante debemos recordar que esta cantidad es sólo una parte de sus ventas dado que sólo pasaban por el notario o por la mesa del Justicia aquellas transacciones que generaban deuda por impago o inseguridad en el cobro. De hecho, los documentos que nos muestran este negocio no son compraventas sino reconocimientos de deuda por parte del comprador ante notario o ante el Justicia de la villa. Por esta misma razón, un 30\% de las deudas pañeras que nos han aparecido de Martí, las tenía con musulmanes de la zona, y no tanto porque estuviera especializado en la venta a este colectivo, sino más bien por su alto índice de impago o retraso (así lo confirma su viuda tras la redacción del testamento de su esposo: resten deutes en quantitat prou gran e lo dit testador haia escrit en son llibre que li són deguts per moros de Guadalest, Confrides, Vall de Seta e de molts altres llocs, APPV, 23.807). Muchas otras transacciones no se registraban en documento notarial o judicial (por lo que ello suponía de gasto para ambas partes), sino en los libros de contabilidad privados, que tenían validez legal en caso de juicio. Sin embargo, lo que no podemos precisar es el porcentaje de cada una de estas partes para conocer el volumen real de producción y venta de paños de Martí, pero sin duda sería mucho mayor a la que ofrecen estos reconocimientos de deuda conservados.

35 Sólo hemos localizado una venta de paño menor al deiciocheno, un dieciseiseno tintado de color amarillo oscuro, valorado en 140 sueldos, APPV, 23.802, Guillem Peris, 1473-XI-16.

${ }^{36}$ Casi 3.000 sueldos si sumanos el valor aproximado de los paños y alnas en stock.

37 En las villas pañeras de nuestra área, hemos localizado siempre el tintado sobre el paño ya elaborado, y no sobre lana o sobre hilo, como ocurría en otras regiones. 
contacto con el mercado, con los posibles clientes, venta final del paño ya tintado) y que no interveía en el complejo trabajo de la tintorería; por otra, un socio (o socios) encargados directos del tintado, y que aportaban el saber técnico, la mano de obra auxiliar (mozos, aprendices, familiares) y la infraestructura necesaria para llevarlo a cabo (el casal del tinte con todos sus instrumentos) ${ }^{38}$. Los socios «capitalistas» eran siempre grandes pelaires o pañeros emprendedores -como el mismo Martí-, con diversificados negocios y amplias empresas que les permitían estas inversiones, mientras que los socios «laborales» eran lógicamente tintoreros profesionales -en alguna ocasión denominados como «maestros», y con amplia tradición familiar en el tintado- que contaban con mano de obra complementaria y que disponían de las instalaciones necesarias. Ambas partes, socio capitalista y socio laboral, salían beneficiados del encuentro: por un lado, los grandes pañeros podían tintar sus tejidos para beneficiarse así de las ventajas que ello les suponía en el mercado, por otro, los tintoreros garantizaban su continuidad laboral mediante los constantes encargos que generaban los drapers y el abastecimiento, en condiciones muy favorables, de los productos tintóreos de alto precio.

En relación a Martí, sabemos que suscribió al menos un par de estas compañías, y que en una de ellas estuvo asociado con el activo tintorero contestano Pere Maroquí, según consta en un documento notarial de cancelación de dicha compañía que se produjo años después de la muerte de Martí. La lectura del documento en cuestión nos indica que esta compañía fue de larga duración, y que sobrepasó el modelo de uno o dos años que parecía imponerse en este tipo de asociaciones, a juzgar por las numerosas conservadas ${ }^{39}$. Bernat, como pelaire, se encargaría de suministrar a su socio los paños sin tintar (producidos por él mismo o por su propio taller, o los elaborados por otros pelaires de la villa con los que Martí tendría relación mediante el suministro de materia prima u otros productos como el aceite); como draper, Martí, y con su experiencia en la comercialización de tejidos y otros productos, se encargaría de vender los paños ya tintados por Maroquí en el amplio mercado regional de la pañería contestana, y se encargaría además de la gestión y la contabilidad de dicha compañía. Sólo mediante estas asociaciones, y esta división del trabajo dentro de las mismas, podemos entender y explicar numerosas deudas que algunos artesanos (tanto de Cocentaina como de otras villas) habían contraído con Martí por el tintado de sus paños: él, encargado de la contabilidad de la compañía, era quien denunciaba los impagos o

${ }^{38}$ Para más información sobre estos modelos de gestión, LLIBRER, J. A., «La formación de compañías para el tintado de paños. El caso de Cocentaina en el siglo XV», Anuario de Estudios Medievales, 2011, 41/1, pp. 59-72.

${ }^{39}$ La transcripción de la parte clave del documento es la siguiente: Nos, Nicholana, uxor quondam Bernardi Marti, draperii, vicina ville Cocentayne, ex una, et Petrus Maroqui, tintorerius eiusdem ville vicinus, ex altera partibus, gratis et ex nostris certis scientiis et spontaneis voluntatibus (...), absoluimus, difinimus, quitamus, ratione et ex causa campanyie que in diebus preteritis et de tempore quo dictus Bernardus Marti vivebat, et ego, dictus Maroqui, erat, et dictam companyiam predictam molto tempore inter nos portavimus. Los activos drapers contestanos Joan Sancholí y Onofre Calatayud, de parecidas características empresariales a Martí, son testigos de tal cancelación. APPV, 23.819, Guillem Peris, 1496-I-21. La intensa y larga relación profesional con el tintorero Maroquí se confirma por su presencia como testigo en algunas ventas de aceite que realiza Martí desde 1479 a 1482, vid. las prosopografías de ambos, Llibrer, J. A., Industria textil y desarrollo regional..., vol. II, pp. 173-188. 
la morosidad ante el Justicia local ${ }^{40}$. Estos ejemplos, y otros muchos documentados, nos confirman que estas compañías no sólo tintaban los paños elaborados por los mismos socios, además ofrecían el servicio de la tintura a otros artesanos de la misma villa y de las otras comunidades pañeras del área, aprovechando así una demanda en aumento de tejidos coloreados ${ }^{41}$.

También gracias a estas relaciones laborales, a estas polivalentes compañías, podemos entender y valorar la presencia de libros de contabilidad en las botigas de estos artesanos emprendedores (como veíamos antes para el ejemplo de Martí: llibres manuals de la draperia e companyia del tint e altres negocis e negociacions) dado el nivel de capitalización que exigían estas empresas textiles y la gran cantidad de operaciones que en ellas se llevaban a cabo (tejido, tundido, abatanado, tintado). Esta última es una cuestión determinante para acercarnos al nivel de las empresas pañeras gestionadas por los artesanos más emprendedores. En referencia a nuestro protagonista, sabemos - de nuevo gracias a su testamento-, que en otra companyia del tint, que había suscrito junto a su vecino Jaume Moltó, sin duda otro de los paraire-drapers emprendedores de la villa ${ }^{42}$, se habla de un capital de 14.000 sueldos, según constaba en un libro de contabilidad de Moltó (aunque no podemos precisar si la cifra correspondía al volumen de negocio hasta esta fecha o al beneficio de dicha compañía ${ }^{43}$. En cualquier caso, vemos que la cantidad no era despreciable, y que generaba una exigencia inversora sólo al alcance de unos pocos artesanos-empresarios, que en escasas semanas debían desembolsar cantidades superiores al millar de sueldos ${ }^{44}$.

Producir paños, tintarlos y venderlos, éstas eran las tres actividades básicas de la empresa de Martí, pero que exigían amplias relaciones con otros artesanos. Ya hemos visto cómo se gestionaban estas relaciones con el tintado, pero de menos información disponemos para conocer la producción pañera de nuestro pelaire. A pesar de ello, algunos indicios nos remiten a las relaciones de Martí - lo que también ha sido demostrado para otros artesanos emprendedores- con otros pelaires de empresas más modestas, que podían trabajar bajo encargo para nuestro protagonista. Así se despren-

${ }^{40}$ Unos ejemplos de estas interesantes deudas: el sastre contestano Jaume Daroca confiesa deberle 10 libras y 8 sueldos, restantes de mayor cantidad por tintado: extantes maiori quantitate de tintis per vos michi factis in pannis meis diversorum colorum (APPV, 23.802, 1473-XI-3). Años después, el Justicia de la villa condena a Bartomeu Ager, tejedor vecino de Alcoi, a pagarle 65 sueldos por el tintado de un paño 21 no verde oscuro, per causa de tintes de un vintihú vert scur que aquell -Bernat Martí- li tenyí (Arxiu Municipal de Cocentaina, AMC, Cort de Justícia, 47/1, 1479-V-6). Sólo tres meses después Joan del Puerto, agricultor vecino de Cocentaina, es condenado por el Justicia a pagarle 28 sueldos por tintado: deguts de tintes de un drap (Íd., 1479-VIII-28). Al final del testamento de Martí, Joan Bernat, de Albaida, confiesa que le debía 1.215 sueldos, restantes de una cantidad mayor, por tintes; Joan Buera, pelaire-draper contestano, confiesa deberle 124 sueldos, parte de una cantidad mayor por el mismo concepto (APPV, 23.807, 1482-III-18).

${ }^{41}$ Llibrer, J. A., «La formación de compañías...», pp. 60-69.

${ }^{42}$ Sobre este activo artesano de Cocentaina, vid. su prosopografía en Llibrer, J. A., Industria textil $y$ desarrollo regional..., vol. II, pp. 196-204.

${ }^{43}$ APPV, 23.807, 1482-III-18. Como Moltó no es tintorero debemos pensar que la compañía fue suscrita por los dos drapers junto a un tintorero que no es citado por no estar encargado de la parcela administrativa. Hemos documentado tal situación en otras compañías, Llibrer, J. A., «La formación de compañías...», pp. 66-71.

${ }^{44}$ Así ocurre con las compañías conocidas en Cocentaina en esta cronología, Id., esp. pp. 59-70. 
de, por ejemplo, de algunas ventas de paños realizadas por Bernat donde aparecen dos compradores, y ambos de distinto origen: en estos casos, uno de los compradores es siempre un pelaire de Cocentaina, aunque en el mismo documento se reconoce que el paño es en realidad para el otro comprador (con frecuencia vecino de otra vi1la); este tipo de transacción -frecuente también entre otros grandes pañeros- parece mostrar una relación laboral o profesional entre los pelaires implicados: ¿qué función tenían estos otros pelaires «supuestos compradores»? ¿Eran simples intermediarios o más bien eran colaboradores de Martí en la producción de los paños? Si realmente era Bernat quien, por su experiencia mercantil, se encargaba de la venta directa, no parece tener sentido la función de aquéllos como intermediarios, ¿no podrían ser más bien artesanos asociados a Martí en relación a la producción del tejido? Por otro lado, la presencia repetida de otros pelaires de la villa como testigos en muchas de las transacciones de nuestro draper, tanto de paños como de otros bienes, parece también indicarnos cierta relación entre ellos, como habíamos confirmado en el caso del tintorero Pere Maroquí. No puede ser casual, por ejemplo, que pelaires vecinos como Pere Cebrià, Bernat Ripoll, Guillem Ferrer, Bernat Figuerola, Bernat Tomàs o Pere Sala, se presenten como testigos (y algunos más de una vez) ante el notario cuando Martí cierra alguno de sus negocios y especialmente las ventas de paños. Estas presencias no pueden ser fruto de simples relaciones de vecindad, traslucen sin duda algún tipo de relación económica entre los artesanos.

Por otro lado, algunos testimonios documentales manifiestan que Bernat Martí, y otros emprendedores como él, elaboraban paños sin que hubieran sido acabados, y no para su venta en el mercado sino para otros pelaires vecinos. Así se deduce de los mismos documentos de compraventa o de reconocimiento de deuda por paños: en muchas ocasiones los compradores son pelaires de empresas más modestas -así lo comprobamos por sus prosopografías-; pero además, en estos casos, Bernat les vende paños sin tintar y sin tundir, lo que la documentación denomina crus («crudos»), és decir, paños que lógicamente tundirían los pelaires compradores ${ }^{45}$. Esta estrategia empresarial no era esporádica para estos emprendedores (en total, un tercio de las ventas de paños que hemos documentado de Bernat son a artesanos del textil y en estas mismas condiciones), lo que sin duda manifiesta la polivalencia de sus empresas y su capacidad de adaptación tanto a la demanda interna como externa.

Y esto nos lleva a una conclusión fundamental: sólo si Martí -y el resto de pañeros más activos- gestionaba o controlaba el tejido mediante encargos a tejedores locales (recordemos que en la villa hemos localizado en estos años a unos cuarenta tejedores), podía llegar a mantener un elevado nivel de producción, y así vender a estos otros pelaires los paños sin terminar; todo ello nos permite intuir las relaciones de Martí con urdidores y tejedores, e incluso con un amplio grupo de hiladoras -los instrumentos hallados en su casa no hacen sino confirmar estas hipótesis- para que le proporcionaran paños crudos que después él mismo prepararía y tundiría, o que podría vender a terceros pelaires. Los contactos de Martí eran claros, por una parte, hacia las primeras fases de tratamiento de la lana, su hilado y su tejido; pero, por

${ }^{45}$ Martí vende este tipo de paños, por ejemplo, a los pelaires Francesc Porta, Guillem Vilaplana, Joan Abat -éste último de Alcoi-, o al draper Nicolau Borras, Llibrer, J. A., Industria textil y desarrollo regional..., vol. II, pp. 179-188. 
otra, eran también evidentes, con relación a otros pelaires o tundidores, e incluso tintoreros. Finalmente, era el propio Martí, el que contactaba con los compradores, los consumidores de sus paños, vecinos de distintos oficios (sastres, notarios, agricultores, albañiles, zapateros... tanto cristianos como musulmanes) que poblaban las villas del sur del reino.

Y llegados a este punto, es necesario que nos detengamos en un apartado básico aún no tratado: el acceso a la materia prima. Si Martí es gestor de una amplia empresa de producción y venta de paños, necesita un abastecimiento regular y constante de lana. Lana que debía ser distribuida entre hiladores/hiladoras y, posteriormente, tejedores para su elaboración (la presencia en su casa de abundante fibra hilada así parece confirmarlo). También en este aspecto, la actuación de nuestro pañero seguía la estrategia del selecto grupo de artesanos más activos y emprendedores, que accedían de forma directa a la materia prima sin la acción de mercaderes externos o de otro tipo de intermediarios. En efecto, las numerosas compraventas de lana localizadas en Cocentaina para esta cronología nos muestran, en primer lugar, cómo este mercado estaba gestionado y controlado por los grandes artesano-pañeros locales (el $90 \%$ de los adquisidores de lana a gran escala son estos activos pelaires y drapers de la propia villa) y, en segundo lugar, nos muestran cómo estos mismos emprendedores contactaban directamente con los propietarios de las cabañas (ubicados generalmente en los valles y las sierras de estas comarcas del centro-sur valenciano: Vall de Seta, Guadalest, Gallinera, la Serrella, Mariola, Montcabrer.... ${ }^{46}$, a quienes compraban anticipadamente la lana adelantando una parte importante de capital. Pero además, llegaba a ser frecuente incluso que muchos de estos pelaires más activos adquirieran importantes cabañas de ganado lanar - con varios centenares de cabezas- para acceder a la materia prima en condiciones aún más ventajosas, $\mathrm{y}$ además para poder intervenir favorablemente en el mercado de distribución local de esta materia bàsica ${ }^{47}$.

En relación a Martí, las fuentes -tan prolijas para otros conceptos y actividades-, han sido escasas en este apartado, y guardan un silencio que, como veremos, resulta también significativo. Sólo conocemos de nuestro protagonista un par de transacciones, una compra y una venta de lana. En diciembre de 1472, Martí compra anticipadamente, la lana de los rebaños de Yaye Mazuet (de quien desconocemos su origen), y le adelanta 135 sueldos; Mazuet se compromete a entregarle la fibra en junio próxi$\mathrm{mo}^{48}$. De nuevo nos encontramos ante una compra a crédito como parte de una estrategia ya conocida, y típica de estos pañeros más dinámicos. El siguiente testimonio es

${ }^{46}$ No olvidemos que todas estas zonas eran, al menos desde la conquista cristiana, de clara vocación ganadera, vocación que desde el siglo XV se reorientó a satisfacer una demanda de lana en constante aumento por parte de las pequeñas ciudades del área como Cocentaina, Alcoi, Ontinyent, Bocairent...

47 La documentación es también abundante en este aspecto: sólo en el año 1472, sabemos que los activos pelaires contestanos Jaume Siurana y Joan Buera, eran propietarios de una cabaña de 413 cabezas; Bernat Figuerola, otro destacado pelaire de Cocentaina, tenía unas 300 cabezas; y el importante pañero Bartomeu Maiques poseía una cabaña de algo más del millar de unidades; otros poderosos propietarios eran los pañeros Joan Pérez de Requena, Bernat d'Estanya, Nicolau Borràs, Pere Cebrià o Bernat Cirera. De Martí no conocemos datos sobre ganado pero como su padre era pastor, cabe deducir un contacto directo con rabaños y lanas. Sobre el mercado de lana y ganado, Llibrer, J. A., Industria textil y desarrollo regional..., vol. I, pp. 354-405.

${ }^{48}$ APPV, 23.801 (1472-XII-17). 
ya de 1479, se trata de una denuncia que Martí interpone ante el Justicia local por una venta de tres arrobas de lana a un pelaire vecino, Bartomeu Nogueroles, porque éste aún no le ha pagado ${ }^{49}$. Aquí vemos cómo Martí distribuía también lana en pequeñas cantidades a otros pelaires vecinos, actuación típica, a su vez, de estos emprendedores. La adquisición de lana al por mayor, o su propiedad mediante el control de las cabañas, les permitía posteriormente distribuirla entre los artesanos más modestos con quienes adquirían vínculos de dependencia que contribuían a consolidar el papel de estos artesanos más activos como auténticos gestores de la producción pañera local ${ }^{50}$. $\mathrm{Su}$ solvencia económica les permitía este acceso sin restricciones a la materia prima, y el mantenimiento de una producción acorde a la demanda.

\section{MÁS ALLÁ DEL SECTOR TEXTIL: EL MERCADO AGRÍCOLA Y EL CREDITICIO}

Como ya hemos visto, la producción y venta de paños o la distribución de lana, no eran los únicos negocios que ocupaban el tiempo de Martí. Tanto su amplia prosopografía como su detallado inventario nos confirman una intensa actividad distribuidora de productos agrícolas. La compraventa de estos productos -aceite, cereales, vinosupone casi la mitad de las noticias que conocemos de Martí (46 de 106), sobrepasando incluso las noticias referidas a sus negocios textiles, aunque el valor monetario sea sin duda mucho menor en este mercado agrícola.

En este campo, la estrategia de nuestro pelaire era similar a la observada en la lana: compra anticipada del producto antes de la cosecha, y generalmente en grandes cantidades, para después llevar a cabo una venta al por menor que permitiera beneficios. Vimos que Martí disponía en su casa de diversos espacios específicos de almacén para cada producto: celler de l'oli (donde tenía 13 tinajas, 7 grandes y 6 pequeñas), celler del vi (con 3 botas grandes, 3 toneles y 6 tinajas), y una habitación donde concentraba los cereales ${ }^{51}$.

Podemos conocer bien la práctica mercantil de Martí gracias a las fuentes notariales, dado que cada año pasaba por el notario para escriturar las ventas anticipadas de estos productos agrícolas. Esto suponía, en ocasiones, ir a la mesa notarial más de una vez al día (lo que era frecuente para la adquisición de aceite), y que le exigía inversiones también elevadas dado que solía pagar por adelantado el precio total. Sólo un ejemplo indicativo: entre el 22 de agosto y el 22 de diciembre de 1474, Bernat llega a comprar anticipadamente 196 arrobas de aceite (¡2.380 litros!), lo que le supuso un desembolso de unos 1.000 sueldos en sólo cinco meses. En los mismos

49 AMC, Cort de Justícia 47/1 (1479-XI-5).

${ }^{50} \mathrm{La}$ documentación nos ha mostrado también frecuentes ventas al por menor de lana (entre dos y cinco arrobas) realizadas por los emprendedores locales, y adquirida por pequeños artesanos -así lo deducimos por la escasa actividad que testimonian sus prosopografías-, que no son sino una redistribución interna de la materia prima para activar los numerosos talleres locales.

${ }^{51}$ En el momento de la redacción tenía en stock 243 litros de aceite (cifra escasa a causa de lo avanzado del año), 1.800 litros de vino y 6.000 litros de trigo. 
contratos se acuerda que los vendedores llevarán los productos a la botiga de Martí tras la cosecha.

De los tres productos comentados, será en el aceite, por el hecho de tratarse de una materia prima para el tratamiento de la lana y el paño, donde Bernat dedique mayor esfuerzo e inversión, hasta llegar a convertirse en un auténtico agente redistribuidor del mercado comarcal: recibido el aceite en los meses de enero a abril, lo almacenaba en sus tinajas y un par de meses después comenzaba a venderlo a particulares -entre ellos, muchos pelaires contestanos-, y a un precio que superaba, primero en un par de sueldos, el de su adquisición anticipada, y que iba encareciendo a medida que pasaban los meses (hasta llegar a superar en más de 4 sueldos su precio inicial). El beneficio era claro, y el volumen de muchas ventas concretas llegaba a superar con frecuencia el de su adquisición: en un solo día, el 11 de mayo de 1479, llegó a vender 336 arrobas (4.080 litros) en cuatro transacciones; y si sumamos lo vendido ese mes, superó las 500 arrobas ( $; 6.000$ litros!), lo que le supuso un beneficio de 3.350 sueldos. Y sólo dos meses después, Martí ya aparece ante la mesa del notario comprando de forma anticipada el aceite de la próxima cosecha ${ }^{52}$. Ello le obligaba a extender su red de influencia y de relación económica muchos kilómetros más allá de Cocentaina en busca del gran acopio de aceite necesario: así, lo encontramos comprando dicho producto en villas como Catamarruc, Planes o Almudaina. Por todos los datos aportados, podemos deducir que no sólo sus adquisiciones sino también sus ventas eran al por mayor, lo que nos habla tanto del amplio volumen del negocio, como del rol y la influencia que este draper iba adquiriendo en el mercado comarcal.

Estrategia similar utilizaba con los cereales y el vino: adquisición en grandes cantidades y distribución progresiva a un amplio grupo de clientes (las comunidades musulmanas para el cereal, vecinos cristianos de villas cercanas, para el vino). No obstante, en todos los casos, el aprovisionamiento de los productos mediante el sistema de compra anticipada, que no era sino una compra a crédito, le exigía un nivel de capitalización nada desdeñable, y sólo al alcance de aquellos artesanos con empresas más solventes ${ }^{53}$.

Tal vez parte del capital y de la solvencia de Martí venía de su negocio crediticio censalista, donde también había ido desarrollando una progresiva estrategia de adquisición hasta llegar a constituir una amplia cartera que le suponía cada año, en concepto de pensiones pagadas por los deudores, un importante capital (en 1482, estos ingresos le generaron una cantidad cercana a los 2.300 sueldos). Hasta el año 1481,

${ }^{52}$ Para los detalles de compraventas, precios y agentes, Llibrer, J. A., Industria textil y desarrollo regional..., vol. II, pp. 179-188.

${ }^{53}$ Sólo un ejemplo de su dedicación a la distribución cerealícola entre musulmanes de las comarcas vecinas -en un radio de acción que se extendía 20 km más allá de Cocentaina: en un mes (entre el 14 de enero y el 19 de febrero de 1473), Martí realiza siete ventas de cereal (trigo y cebada) a mudéjares de distintas aljamas; en cada transacción Martí vende simpre entre 2 y 4 cahíces, con precios -según tipo de cereal- que se sitúan entre los 150-200 sueldos. No obstante, también es documentado vendiendo en mayores cantidades: el año siguiente suministra 13 cahíces de cebada a dos musulmanes de Catamarruc (a $15 \mathrm{~km}$ de Cocentaina) por 350 sueldos (1474-III-30). En relación al vino, su distribución la realiza, como es lógico, a compradores cristianos de villas más cercanas (como Alcoi o Benifallim), y en cantidades destacables que van de los 200 a 400 litros, con precios que siempre sobrepasan el medio centenar de sueldos, LliBrer, J. A., Industria textil y desarrollo regional..., vol. II, pp. 179-188. 
momento en que adquirió el último de los títulos, Martí llegó a tener 44 censales, lo que le exigía un libro de contabilidad donde poder llevar a cabo el seguimiento riguroso y escrupuloso de los pagos anuales de los deudores. Así aparece en su inventario: fonch atrobat un capbreu o memorial de censals, en lo qual són escrits los censals següents; y a continuación el notario, a lo largo de diez páginas de su protocolo, va anotando cada uno de los títulos adquiridos. Gracias a esta valiosa información podemos conocer su estrategia crediticia y su amplio patrimonio censalista, observando así lo variado de sus negocios y su diversificación empresarial.

Aunque algunos títulos fueron adquiridos en las décadas de 1460-1470, será entre 1480-1481 cuando nuestro paraire-draper complete una auténtica estrategia de adquisición: sólo en estos dos años compra 17 de sus 44 títulos; es decir, cuando su carrera profesional en el mundo textil y en su mercado ya está claramente consolidada, decide una poderosa inversión censalista que actúe como complemento de su negocio textil y que asegure un futuro rentista acorde con la posición de privilegio que Martí había estado buscando en su comunidad. Así, este draper contestano llegó a invertir en censales 25.580 sueldos, fortuna que equivalía a la de muchos señoríos, alquerías o amplias propiedades inmuebles. Sin embargo Bernat, a diferencia de otros miembros de la élite artesanal contestana, no incluía entre sus inversiones un gran patrimonio fundiario (sólo era propietario de dos casas en la villa y de una parcela de viña), él se había decantado por una sólida cartera censal.

Los 25.580 sueldos los había ido invirtiendo en préstamos de carácter privado y con volumen de capital medio (sólo en 5 de sus 44 títulos sobrepasó los 1.000 sueldos de capital; y sólo en una ocasión intervino en deuda pública prestando 2.000 sueldos a la misma villa de Cocentaina). Este crédito censal servía a Martí para crear una red de dependencia hacia algunos artesanos vecinos, ya que seis pelaires y un sastre aparecen como deudores, con lo que ello podría implicar en relación a la distribución de lana o al trabajo de producción de paños ${ }^{54}$. Estos se endeudaban con capitales parecidos, entre 300 y 600 sueldos, con un interés del 8,33\%, lo que implicaba unas pensiones anuales en torno a los 40 sueldos. Por lo que respecta a la geografía del mercado crediticio de Martí, sus préstamos privilegiaban el marco local pues el 75\% de sus deudores residía en Cocentaina o en su morería, sin embargo no descartaba prestar en zonas más alejadas como Muro, Planes, Penàguila o Bocairent.

Por todo ello, Bernat nos aparece como ejemplo de las tendencias inversoras de muchos de los artesanos empresarios de estas pequeñas ciudades pañeras valencianas: la seguridad ante el riesgo que suponía la producción textil o el comercio, por las fluctuaciones de precios y demanda, eran causas que animaban a estos activos pelaires y drapers a desviar capitales para emplearlos en el crédito censal, inversión perfectamente compatible con el desarrollo de las actividades artesanales y de otros negocios mercantiles. No olvidemos que desde finales del siglo XIV el censal había generado un mercado tan denso y articulado que podía competir con el de la tierra a la hora de captar inversiones, dado que suponía algunas ventajas frente a las rentas inmobiliarias (pensiones estables y alto interés frente a las fluctuaciones de las

${ }^{54}$ Se trata de los pelaires Joan Sancho, Joan Navarro, Joan de Torres, Joan Just, Joan Ager de Alcoi, y Jaume Martí; el sastre es Francesc Alfonso. A juzgar por sus escasas y limitadas prosopografías bien podrían haberse establecido relaciones laborales con su acreedor. 
cosechas $)^{55}$. A todas luces, ésta era una manera de obtener beneficios periódicos con poco riesgo, en la medida que estaba respaldada por un eficaz mecanismo judicial que aseguraba tanto la percepción de las pensiones como la recuperación del capital mediante embargo de bienes del deudor insolvente. Por ello, muchos de los artesanos emprendedores nos aparecen como auténticos profesionales del crédito que, más allá de una intervención esporádica, consideran el censal como una inversión con clara continuidad en el tiempo. Así, no es extraño que junto a Martí, los Pérez de Requena, los Maiques, los Calatayud, los Moltó o los d'Estanya, élite de los pelaires y drapers contestanos, por sólo comentar los de esta villa y los ya citados por otros negocios, conformaran también importantes carteras censalistas, con inversiones totales que estaban entre los 10.000 y los 60.000 sueldos $^{56}$.

\section{UNA VALORACIÓN DE LOS DATOS}

Tras todo lo analizado anteriormente, la estrategia empresarial de Martí, y de buena parte del colectivo de los artesanos-emprendedores, comienza a quedarnos clara: formados en la pelairía y, dentro de ésta, especializados con frecuencia en el tundido, comenzaron a gestionar parte del proceso de elaboración del paño, en primer lugar desde la adquisición y distribución de lana y, posteriormente, en los procesos de acabado, para poder así controlar su propia producción pañera y garantizarse cierto privilegio ante el mercado, de ahí su interés, por ejemplo, en el proceso de la tintura o el abatanado.

En el caso de Martí, encargando el tejido del paño que él posteriormente junto a otros pelaires trataría, conseguía mantener un nivel de producción constante; además, su relación con el tintado, a través de compañías con tintoreros, le permitía, por una parte, aportar el valor añadido a sus paños, mejorando su carácter merceológico y, por otra, gestionar el tintado de paños para otros artesanos, un proceso caro y costoso que le producía interesantes beneficios pero que además consolidaba su privilegiada posición en el mercado pañero comarcal. En complemento a este conocimiento del mercado, se convirtió en agente redistribuidor de aceite y otros productos agrícolas (mediante un sistema de compra anticipada a crédito), que cada vez más hacía decantar su empresa hacia el ámbito mercantil. La documentación manifiesta esta evolución mediante el uso del término draper, es decir, pañero comercializador. Así su botiga se convirtió en espacio de almacenaje y distribución -y no sólo al por menor-, tanto de tejidos como de esos productos. Además, la amplitud de su mercado iba mucho más allá de lo local, vendiendo sus manufacturas y productos en ciudades, villas y lugares alejados decenas de kilómetros de su casa en Cocentaina.

${ }^{55}$ Sobre la articulación y ventajas de este mercado, FuRIó, A., «Crédito y endeudamiento: el censal en la sociedad rural valenciana (siglos XIV-XV)», en Señorío y feudalismo en la Península Ibérica (siglos XII-XIX). Zaragoza, 1993, pp. 501-534; y también FuRIó, A., «Le crédit dans les registres notariaux de la région de Valence au Bas Moyen Âge», Melanges de l'Ecole Francaise de Rome, 2005, 117, pp. 407-439.

${ }^{56}$ Sobre el mercado crediticio de estos otros artesanos emprendedores, LLIBRER, J. A., Industria textil y desarrollo regional..., vol. I, pp. 557-598. 
Un análisis más detallado de sus actividades mercantiles nos permite precisar que su mercado llega a conformar hasta tres niveles diferentes de articulación: en primer lugar el estrictamente local, activado por unas manufacturas en constante crecimiento y por una comunidad artesanal muy amplia; en segundo lugar un nivel comarcal hacia centros en un radio de acción de unos 15-20 km, con villas tan importantes como Alcoi o núcleos como Penàguila, Planes, Almudaina, Catamarruc y otras alquerías o aljamas de la Vall de Seta; y finalmente un tercer nivel supracomarcal con distancias mayores a los $20 \mathrm{~km}$, como lo demuestran las ventas registradas de Martí a vecinos de ciudades como Ontinyent o Xàtiva, y de villas como Banyeres, Rugat, Llutxent, las alquerías de la Vall de Guadalest, Confrides, Castalla, Biar y centros costeros más alejados como Vila Joiosa ${ }^{57}$. Y es precisamente el mercado de paños el más extenso, el que llega a las villas más alejadas, a diferencia de su mercado de productos agrícolas que queda en buena medida restingido a los dos primeros niveles. No olvidemos tampoco su mercado del crédito, que en ocasiones se extiende por estos tres ámbitos creando una red capilar de dependencia y de circulación de rentas, productos y manufacturas de ámbito supracomarcal.

El ejemplo de Martí, junto a otros ya citados, nos muestra que en el centro de estos mercados interiores se situaban con frecuencia estos artesanos emprendedores de clara vocación mercantil, con un rol motor que, aunque alejado de los grandes operadores económicos de los circuitos internacionales, tendía a dinamizar la economía y el sistema productivo de estas pequeñas ciudades mientras facilitaba la articulación de estos mercados supracomarcales.

En efecto, como hemos ido viendo a lo largo de nuestro trabajo, lo más interesante del caso Martí es que no se trató de un ejemplo aislado. Las estrategias artesanales y mercantiles de Bernat las hemos documentado también para otros emprendedores de estas villas pañeras como Cocentaina, Ontinyent o Alcoi. El nivel de capitalización de sus empresas les permitía un acercamiento a las inversiones en infraestructura industrial (tintorerías, batanes, tiradores, almazaras) que ampliaban y mejoraban la producción y su nivel merceológico. Fue precisamente este interés en una mejora del nivel productivo el que está en el origen de esta élite artesanomercantil. ¿Pero cómo se acabó gestando este sector emprendedor? ¿Cómo se generó esta jerarquización en el seno de estas comunidades manufactureras de las pequeñas ciudades pañeras valencianas? En el paso de una producción doméstica a una producción para el mercado - que se gesta ya desde la segunda mitad del siglo XIV-, un pequeño grupo de familias o de linajes, a causa de determinadas ventajas debidas a distintos factores (saber técnico, propiedad de amplio patrimonio inmueble, participación favorable en el mercado del crédito, contacto con el mercado a través del circuito de productos agrícolas) pudieron ampliar el volumen de negocio de sus empresas acercándose ventajosamente al mercado de materias primas y al dominio de determinadas instalaciones necesarias a una producción para mercados supralocales. Una interesante

${ }^{57}$ En esta última ciudad costera, y una de las más alejadas de Cocentaina, los negocios de Martí no son esporádicos: es nombrado procurador por Jofre Cetina, de aquella villa, en 1471 (APPV, 23.800, 1471-VII-5); años más tarde el propio Bernat nombrará procurador a Llorenç Martí, tambén de Vila Joiosa, para que le cobre allí unas deudas (APPV, 23.804, 1479-III-14); en 1481 Llorenç sigue siendo su procurador y reclamando nuevos pagos (APPV, 23.805, 1481-IV-6). 
combinación de conocimientos técnicos junto a capacidad de inversión les permitió poco a poco gestionar una mayor cantidad de operaciones del proceso pañero. Con una mayor iniciativa emprendedora y con una amplia gestión empresarial daban la unidad necesaria al proceso de elaboración textil, un proceso eminentemente fragmentado por las numerosas operaciones que implicaba. No era por tanto casual que fueran generalmente los pelaires o tundidores los que acabaran protagonizando este proceso. La mayor especialización técnica de éstos fue la que en parte les permitió adquirir una posición de privilegio en todo el proceso productivo, esencialmente en las trascendentales fases de acabado. Incluso la posición estratégica del tundido en este conjunto de operaciones finales, hacía de esta tarea una de las claves no sólo para el dominio de la refinición sino también para el acercamiento al mercado, a la esfera mercantil en la que acabaron implicándose intensamente muchos de estos pelaires emprendedores que terminaban sus trayectorias empresariales como auténticos mercaderes y con activas botigas donde se sucedían todo tipo de compraventas, recogidas en sus numerosos libros de contabilidad, y que tenían como destino unos mercados interiores supracomarcales cada vez más dinámicos. 